\title{
La ciudadanía y sus límites Jaime Fierro
}

\author{
Ed. Universitaria, Santiago, 2016, 348 págs.
}

\section{Íñigo Álvarez Gálvez}

Universidad de Chile, Santiago, Chile.

Email: ialvarezg@u.uchile.cl

Acaba de ser publicado el libro del profesor Jaime Fierro La ciudadanía y sus límitespor la Editorial Universitaria.Se trata de una obraen la que el autor se enfrenta al espinoso problema de la ciudadanía, que presenta dificultades desde el mismo momento en el que se intenta una delimitación conceptual, dado que no existe un concepto unívoco. Sea lo que sea de esto, lo cierto es que sí está claro lo que el autor busca. La pregunta a la que se trata de contestar es, en palabras de Fierro: “¿Constituye la propuesta de una ciudadanía cosmopolita una alternativa normativamente deseable y empíricamente viable frente al modelo de ciudadanía nacional?” (Fierro 2016: 17). Y la respuesta es igualmente clara: "La propuesta de una 'ciudadanía cosmopolita' -sostiene- es altamente inviable desde el punto de vista empírico, siendo, a su vez, cuestionable desde un punto de vista normativo, especialmente si consideramos el vínculo estrecho entre ciudadanía y democracia” (Ibid: 18). Pero dice más. Según Fierro, "la propuesta cosmopolita, llevada al plano político, corre el riesgo de debilitar la noción misma de ciudadanía y su relación con la democracia” (Ibid: 18). Puestas así las cosas, no es necesario dedicar muchas palabras a explicar la importancia del tema en cuestión: está en juego la noción de ciudadanía y de la misma democracia que se fundamenta en ella.

Para tratar de todo ello, Fierro desarrolla nueve capítulos más (además del que hemos mencionado ya, que es el primero), en los que da cuenta de una gran variedad de asuntos. En el libro se habla de la ciudadanía en Grecia y en Roma, de los conceptos de libertad, de los derechos subjetivos, del feminismo, del multiculturalismo, de la globalización, del cosmopolitismo moral, jurídico y político, además de, por supuesto, la ciudadanía cosmopolita y la relación entre la ciudadanía y la democracia. Cualquiera de estos temas por separado daría para escribir un libro. El de Fierro tiene la virtud de recogerlos todos ellos y ensamblarlos de manera precisa y rigurosa en torno a la pregunta acerca de la ciudadanía cosmopolita. De entre todo ellos, creo que se puede destacar uno que tiene una importancia capital (y la mejor prueba de ello es que aparece de manera transversal en todos los capítulos de la obra). Me refiero a la cuestión de los derechos subjetivos.

El autor habla de ellos en el capítulo tercero, por ejemplo, al tratar de los derechos positivos y negativos (Fierro, 2016: 67); de la noción de dere- 
chos individuales en la antigüedad (Ibid: 68); de las consecuencias no siempre beneficiosas, en particular para la vida comunitaria, que se han derivado de la protección de los derechos (Ibid: 69); o de la necesidad de superar un enfoque basado exclusivamente en los derechos, desde el que se propugne la creación de una ciudadanía responsable y verdaderamente libre. Habla de ellos en el capítulo cuarto (dedicado especialmente a la cuestión de los derechos: "Liberalismo: derechos versus responsabilidades"), donde expone el planteamiento liberal: la doctrina de Marshall acerca de los derechos sociales y del Estado de bienestar (Ibid: 93); la doctrina de Rawls (Ibid: 99); o algunas de las críticas sostenidas por los comunitaristas (Ibid: 110), que tienen que ver con la primacía de lo bueno sobre lo justo y particularmente, de lo bueno formado en comunidad (en función de un marco referencial).Aparecen también al tratar del feminismo, en el capítulo quinto, cuando trata del derecho al voto de las mujeres (de la primera ola feminista de mitad del siglo XIX) (Ibid: 128); del reparto igual de los derechos; o de los derechos diferenciados (en particular de los derechos reproductivos) (Ibid: 140-141). Igualmente, en el capítulo siguiente, dedicado al multiculturalismo, al abordar el asunto de los derechos colectivos yde la dificultad de concebir derechos que se adscriban a un grupo. Y así, al tratar de la globalización (en el capítulo séptimo), cuando se refiere a los derechos sociales de ciudadanía y del papel fundamental que le cabe al Estado-nación (Ibid: 196). También menudean las referencias a los derechos en el capítulo octavo, dedicado al cosmopolitismo,pues forman parte del cosmopolitismo moral, jurídico y político. Vemos igualmente aparecer a los derechos en el capítulo siguiente, en el que el autor continúa tratando la cuestión de la ciudadanía cosmopolita y donde pone de manifiesto cómo sólo desde el Estado-nación es posible garantizar un cumplimiento efectivo de los derechos. Como él dice: "La posibilidad misma de los derechos humanos requiere tanto de la ciudadanía como de la comunidad política nacional que la hace posible” (Ibid: 289). Y, también están los derechos en el último capítulo, en el que se concluye recordando las tres dimensiones de la ciudadanía: derechos y responsabilidades, participación e identidad (Ibid: 310). Como es fácil de apreciar, la referencia a los derechos aparece en un lugar destacadísimo a lo largo de toda la obra.

No quiero decir con esto que el asunto de los derechos sea el único eje vertebrador del libro, pero sí que esta cuestión de los derechos parece ser insoslayable cuando se reflexiona sobre la ciudadanía (cosmopolita). Entre otras cosas, porque es la bandera (o una de las banderas) del liberalismo.

Como se sabe, las doctrinas liberales defienden, desde distintos enfoques, la existencia de una serie de derechos que poseen los individuos y que son previos al poder político y sirven como límites (infranqueables o poco menos) de las decisiones de los gobernantes. Así podemos verlo en Los derechos en serio de Dworkin, en Una teoría de la justicia de Rawls, en Anarquía, Estado y utopía de Nozick, o en Ética y derechos humanos de Nino, por citar alguno de los muchos ejemplos que se podrían ofrecer. En todos estos casos aparecen los derechos como elementos previos al poder, cuya función es precisamente la de limitar ese poder político. Los seres 
humanos, porque son fines en sí mismos, poseen derechos, que la razón descubre, antes y con independencia del poder político. Este es, en términos generales, el planteamiento liberal.Y desde este planteamiento también se sostiene que los derechos más importantes, los derechos fundamentales, humanos (o como queramos llamarlos) tienen unas determinadas características (características que son necesarias justamente para que su función de límites del poder pueda ser eficazmente cumplida). Se dice así, que los derechos humanos son universales, absolutos e inalienables (o irrenunciables).

$\mathrm{Al}$ autor del libro le parece que el puesto que ocupan los derechos es fundamental, pero por otro lado, considera que la propuesta liberal sobre los derechos es discutible (al menos en algunos aspectos). Creo que es una opinión acertada. Es verdad que esta manera de ver las cosas se ha extendido de un modo amplio y se ha aceptado de manera generalizada, pero quizá por lo mismo puede ser saludable someterla a crítica. Jaime Fierro presenta una aguda visión crítica a lo largo de toda su obra, pero es particularmente clara, en mi opinión, cuando trata de la cuestión de la universalidad. De acuerdo con el autor, la defensa de la universalidad de los derechos es problemática, para empezar, porque las diferencias culturales entre unas sociedades y otras son profundas (Fierro, 2016: 238). Por otro lado, los principios que subyacen a esos derechos son entendidos y aplicados también de manera diferente según los lugares; de forma que si las sociedades son diferentes es difícil poner en práctica un conjunto de derechos que, precisamente, no toma en consideración esas diferencias.

Se podría añadir, además, que esta característica de la universalidad es también difícil de sostener desde un punto de vista estrictamente normativo, pues si entendemos los derechos en general (y los derechos humanos en particular) como normas que están insertas en diferentes sistemas o conjuntos normativos (en el Derecho y en la moral, fundamentalmente), parece evidente que la extensión que puedan tener esas normas no puede ser nunca mayor que la extensión que tenga el sistema que los aloja. Afirmar, pues, que los derechos humanos son universales implica afirmar la existencia de un sistema normativo igualmente universal. Pero ¿existe tal?En el ámbito jurídico, los ordenamientos nacionales no son, por definición, universales; y hablar de un ordenamiento internacional no deja de presentar problemas: No existiendo un poder fuerte, por encima de los Estados, quesostenga ese sistema, ya no sólo la eficacia, sino la misma validez de las normas puede llegar a ponerse en cuestión. Y si es posible plantear razonablemente esta duda, porque la respuesta no es obvia, la universalidad queda también puesta en cuestión. Por su parte, en el ámbito moral, las cosas no parecen ser muy diferentes, dado que el debate acerca de lo que es el bien moral está lejos de cerrarse, de manera que la validez universal del sistema tampoco está aquí firmemente asentada. En resumen, las dificultades para sostener sólidamente la existencia de un sistema normativo de validez universal (jurídico o moral), se convierten en dificultades para sostener la validez universal de las normas que se insertan en esos sistemas. 
En cualquier caso, sea lo que sea de un debate así, me parece que lo importante es tomar en consideración el hecho de que la propuesta liberal de los derechos puede ser sometida a crítica y de que tal vez merezca la pena ver si existe otro modo de presentar y defender los derechos. Porque no se trata de denostar los derechos humanos, ni mucho menos. Se trata de tomárselos en serio (como diría Dworkin) y de revisar y mejorar una propuesta que se ha aceptado de forma generalizada, pero que presenta problemas y escollos que reclaman una solución. Si queremos que los derechos humanos sean instrumentos útiles para nuestro mundo debemos adaptarlos precisamente a este mundo, que se caracteriza por el multiculturalismo o la globalización; por las propuestas cosmopolitas, feministas o comunitaristas, a las que se debe dar respuesta; o por las exigencias de un conjunto de responsabilidades que deben formar parte de una ciudadanía adulta y activa. El libro de Fierro es una muestra de cómo se puede afrontar una revisión crítica de los derechos en relación con estas cuestiones. La tarea no es menor, ni en contenido ni en importancia, pues los derechos son y deben seguir siendo uno de los pilares de la ciudadanía, como nos recuerda Fierro en este excelente libro. 